ARTICLE

https://doi.org/10.1038/s41467-019-09083-3

\title{
Electrochemical conversion of methane to ethylene in a solid oxide electrolyzer
}

Changli Zhu', Shisheng Hou ${ }^{1}$, Xiuli Hu', Jinhai Lu', Fanglin Chen (1D ${ }^{2}$ \& Kui Xie (D) ${ }^{1}$

Conversion of methane to ethylene with high yield remains a fundamental challenge due to the low ethylene selectivity, severe carbon deposition and instability of catalysts. Here we demonstrate a conceptually different process of in situ electrochemical oxidation of methane to ethylene in a solid oxide electrolyzer under ambient pressure at $850^{\circ} \mathrm{C}$. The porous electrode scaffold with an in situ-grown metal/oxide interface enhances coking resistance and catalyst stability at high temperatures. The highest $C_{2}$ product selectivity of $81.2 \%$ together with the highest $C_{2}$ product concentration of $16.7 \%$ in output gas (12.1\% ethylene and $4.6 \%$ ethane) is achieved while the methane conversion reaches as high as $41 \%$ in the initial pass. This strategy provides an optimal performance with no obvious degradation being observed after $100 \mathrm{~h}$ of high temperature operation and 10 redox cycles, suggesting a reliable electrochemical process for conversion of methane into valuable chemicals.

\footnotetext{
${ }^{1}$ Key Laboratory of Design and Assembly of Functional Nanostructures, Fujian Institute of Research on the Structure of Matter, Chinese Academy of Sciences, 350002 Fuzhou, Fujian, China. ${ }^{2}$ Department of Mechanical Engineering, University of South Carolina, 300 Main Street, Columbia, SC, 29208, USA. These authors contributed equally: Changli Zhu, Shisheng Hou, Xiuli Hu. Correspondence and requests for materials should be addressed to K.X. (email: kxie@fjirsm.ac.cn)
} 
C onversion of natural gas, mainly $\mathrm{CH}_{4}$, into transportable fuels and chemicals has been largely driven for several decades by emerging industrial trends, including the rising demand for $\mathrm{H}_{2}$ to upgrade lower-quality oils and a global shortage of aromatics caused by shifting refinery targets toward gasoline ${ }^{1}$. Light olefins, mainly $\mathrm{C}_{2} \mathrm{H}_{4}$, as key chemical feedstocks and building blocks, are currently produced through multistage processes from syngas to methanol and then to olefins, although there is some ongoing research of direct conversion of syngas to olefins. This syngas-to-olefin route is dominant in current and near-term industry production ${ }^{2-5}$; however, the carbon-atom efficiency is normally below $50 \%$ in addition to the significant amount of $\mathrm{CO}_{2}$ emission. This mainly arises since the removal of oxygen in carbon monoxide consumes hydrogen and generates water.

Direct conversion of $\mathrm{CH}_{4}$ to $\mathrm{C}_{2} \mathrm{H}_{4}$ is potentially more economical and environmental friendly, but it is a more challenging route. $\mathrm{CH}_{4}$ is a small and stable molecule that exists in nature, and it has strong $\mathrm{C}-\mathrm{H}$ bonds, negligible electron affinity, large ionization energy, and low polarizability. This direct-conversion route can be realized through either oxidative coupling or direct nonoxidative conversion in a heterogeneous catalysis process ${ }^{1}$. It is effective to activate the $\mathrm{C}-\mathrm{H}$ bond of $\mathrm{CH}_{4}$ with oxygen to generate $\mathrm{C}_{2} \mathrm{H}_{4}$; however, over-oxidation of $\mathrm{CH}_{4}$ remains unavoidable, leading to lower carbon atom efficiency. Furthermore, the low $\mathrm{CH}_{4}$ conversion with low selectivity of $\mathrm{C}_{2} \mathrm{H}_{4}$ is another huge challenge $e^{6,7}$. Nonoxidative conversion is a process of dehydrogenation of highly stable $\mathrm{CH}_{4}$ together with selective $\mathrm{C}-\mathrm{C}$ coupling, and a recent work has represented the highest methane conversion (48.1\%) and ethylene selectivity $(48.4 \%)$ at $1090{ }^{\circ} \mathrm{C}^{8}$. In terms of reaction mechanism, the cleavage of a $\mathrm{C}-\mathrm{H}$ bond with $\mathrm{C}-\mathrm{C}$ coupling is indeed an oxidation process for either oxidative coupling or nonoxidative conversion of $\mathrm{CH}_{4}$ according to the charge balance of $\mathrm{CH}_{4} \rightarrow \mathrm{C}_{2} \mathrm{H}_{4}$ transformation. This process would be ideally realized using a conceptually different approach in the form of an efficient electrochemical process with a reaction $\left(2 \mathrm{CH}_{4}+\mathrm{O}^{2-} \leftrightarrows \mathrm{C}_{2} \mathrm{H}_{4}+\mathrm{H}_{2}+\mathrm{H}_{2} \mathrm{O}+2 \mathrm{e}^{-}\right)$for the oxidative coupling of $\mathrm{CH}_{4}$ to $\mathrm{C}_{2} \mathrm{H}_{4}$ or with a reaction $\left(2 \mathrm{CH}_{4}-\right.$ $\left.4 \mathrm{e}^{-} \leftrightarrows \mathrm{C}_{2} \mathrm{H}_{4}+4 \mathrm{H}^{+}\right)$for the nonoxidative conversion of $\mathrm{CH}_{4}$ to $\mathrm{C}_{2} \mathrm{H}_{4}$ through a synergistic control of electrochemical oxidation with in situ catalysis on the electrodes.

Solid oxide electrolyzers (SOEs) have been attracting great interest because of their high efficiencies in converting electricity into fuels and chemicals using renewable electrical energy ${ }^{9}$. The advantages, including long life, versatile scale, and low cost, have also demonstrated huge practical application potentials. They can exploit available high-temperature exhaust heat stream to maximize the electrical energy efficiency, and the high operation temperature of around $800-900^{\circ} \mathrm{C}$ well fits the requirement of catalytic conversion of $\mathrm{CH}_{4}$ to $\mathrm{C}_{2} \mathrm{H}_{4}{ }^{1,10-14}$. In an oxideconducting SOE, the oxygen ions are transported from the cathode through the electrolyte membrane to the anode and form oxygen gas $\left(\mathrm{O}^{2-}-2 \mathrm{e}^{-} \leftrightarrows 1 / 2 \mathrm{O}_{2}\right)$, whilst the cathode would provide suitable sites to accommodate electrolysis reaction that electrochemically extracts $\mathrm{O}^{2-}$ ions from gaseous molecules that contain oxygen atoms under an externally applied potential. As shown in Fig. 1, this unique mechanism provides a possibility of direct utilization of $\mathrm{O}^{2-}$ ions to in situ electrochemically oxidize $\mathrm{CH}_{4}\left(2 \mathrm{CH}_{4}+2 \mathrm{O}^{2-} \leftrightarrows \mathrm{C}_{2} \mathrm{H}_{4}+2 \mathrm{H}_{2} \mathrm{O}+4 \mathrm{e}^{-}\right)$into $\mathrm{C}_{2} \mathrm{H}_{4}$ in the anode. In this case, the electrochemical conversion of $\mathrm{CH}_{4}$ into $\mathrm{C}_{2} \mathrm{H}_{4}$ would be successfully achieved, demonstrating economic and sustainable potential if this process exploits available exhaust heat stream and renewable electrical energy. Similar conversion of $\mathrm{CH}_{4}$ into $\mathrm{C}_{2} \mathrm{H}_{4} \quad\left(2 \mathrm{CH}_{4}-4 \mathrm{e}^{-} \leftrightarrows \mathrm{C}_{2} \mathrm{H}_{4}+4 \mathrm{H}^{+}\right)$would also be feasible in proton-conducting solid oxide electrolyzer while $\mathrm{CH}_{4}$ cracking might lead to coke formation in the electrode.

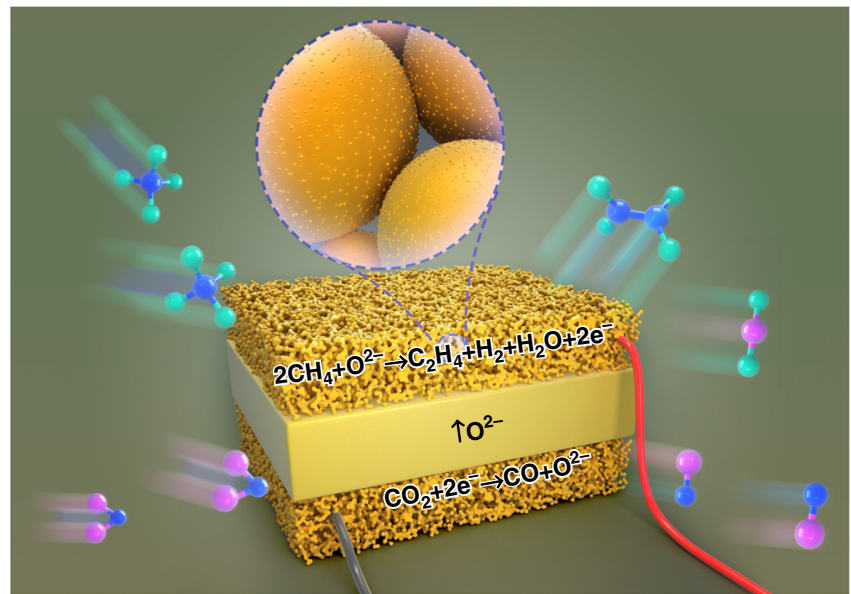

Fig. 1 Electrochemical oxidation of $\mathrm{CH}_{4}$ to chemicals. Here the $\mathrm{CO}_{2}$ is converted to $\mathrm{CO}$ in the cathode while $\mathrm{CH}_{4}$ is converted to chemicals, such as $\mathrm{C}_{2} \mathrm{H}_{4}$ in the anode through a simultaneous process in a solid oxide electrolyzer

Electrochemical oxidation of $\mathrm{CH}_{4}$ to $\mathrm{C}_{2} \mathrm{H}_{4}$ in an oxide-ion conducting solid oxide electrolyzer involves the key step of the first cleavage of $\mathrm{C}-\mathrm{H}$ bonding in $\mathrm{CH}_{4}$ and then the selective coupling of $\mathrm{C}-\mathrm{C}$ bonding for $\mathrm{C}_{2} \mathrm{H}_{4}$ generation through a gaseous electrochemical process in the porous anode. The electrochemical pumping of $\mathrm{O}^{2-}$ ions from the cathode to the anode is indeed a process of generating active oxygen species for $\mathrm{CH}_{4}$ activation and oxidation in the presence of suitable catalysts. Electrochemical oxidation of $\mathrm{CH}_{4}$ with $\mathrm{O}^{2-}$ ions is also a chargerebalancing process while the transformation of $\mathrm{O}^{2-}$ ions to the active interfaces in the anode would involve different types of oxygen species including $\mathrm{O}^{2-}$ and $\mathrm{O}^{-}$ions to initiate the $\mathrm{CH}_{4}$ oxidation process $^{15-19}$. Active metal-oxide interfaces at nanoscale would be ideal to accommodate these oxygen species especially in the form of $\mathrm{O}^{-}$ions. These active oxygen species are one kind of the key active radicals at the confined metal-oxide interfaces to activate $\mathrm{CH}_{4}$ while the electrochemical pumping of $\mathrm{O}^{2-}$ ions would continuously oxidize $\mathrm{CH}_{4}$ in conjunction with gaseous selective coupling to generate $\mathrm{C}_{2} \mathrm{H}_{4}$ in the presence of suitable interface catalysis. Electrochemical pumping of active oxygen species to the porous anode would facilitate the oxidative removal of deposited carbon on the electrode scaffold and therefore enhance the coking resistance during the $\mathrm{CH}_{4}$ cracking process. The applied potentials would split the oxygen-containing molecules such as gaseous $\mathrm{O}_{2}, \mathrm{H}_{2} \mathrm{O}$, or $\mathrm{CO}_{2}$ in the cathode to generate $\mathrm{O}^{2-}$ and simultaneously transport them to the anode. This feature provides the unique advantage of directly electrolyzing $\mathrm{H}_{2} \mathrm{O}$ or $\mathrm{CO}_{2}$ to $\mathrm{H}_{2}$ or $\mathrm{CO}$ to generate oxygen species in conjunction with selective oxidation of $\mathrm{CH}_{4}$ to $\mathrm{C}_{2} \mathrm{H}_{4}$ in the anode.

The incorporation of metal nanoparticles on oxide scaffold has been widely proven to be quite effective to enhance catalytic conversion of $\mathrm{CH}_{4}$ to $\mathrm{C}_{2} \mathrm{H}_{4}$ and the typical metal nanocatalysts, such as iron nanoparticles are normally considered to be suitable to construct metal-oxide interfaces with strong interactions to facilitate the catalysis conversion ${ }^{20,21}$. These metal-oxide interfaces are usually prepared by directly loading metal nanoparticles on porous substrates through an impregnation method. However, long-term stability of metallic nanoparticles simply loaded on oxide surface remains a major challenge. The severe agglomeration and sintering of these nanoparticles lead to catalysis performance degradation especially at high temperature. An alternative method is to dope the iron element in the host lattice of oxide scaffold during the catalyst synthesis in air and then in situ grow the metallic nanoparticles on oxide 
surface through a phase decomposition process under reducing conditions $s^{10,14,22-24}$. The metal nanoparticles directly embedded on porous oxide backbones particularly exhibit enhanced hightemperature stability and coking resistance, which may be due to the strong metal-oxide interactions at the unique interface architectures at nanoscale. Strong interface interactions are also highly favorable for the transfer of oxygen species especially in the form of oxygen ions in this work. These active oxygen species are expected to in situ electrochemically activate and oxidize $\mathrm{CH}_{4}$, and even remove the deposited carbon if present at metal-oxide interfaces in the cathode.

Here, we utilize redox-reversible layered perovskite $\mathrm{Sr}_{2} \mathrm{Fe}_{1.5^{-}}$ $\mathrm{Mo}_{0.5} \mathrm{O}_{6-\delta}$ (SFMO) anode to electrochemically oxidize $\mathrm{CH}_{4}$ to $\mathrm{C}_{2} \mathrm{H}_{4}$ in an oxide-ion-conducting solid oxide electrolyzer. Ceramic SFMO is a mixed conductor with rich oxygen vacancies and we have already shown its excellent activity and coking resistance toward $\mathrm{CH}_{4}$ oxidation ${ }^{25-27}$. We firstly in situ construct metal-oxide interfaces at nanoscale on porous SFMO scaffold by synergistic control of nonstoichiometry and doping of $\mathrm{Sr}_{2} \mathrm{Fe}_{1.5+x} \mathrm{Mo}_{0.5} \mathrm{O}_{6-\delta}(x=0-0.1)$. We then tailor the amount of excess iron to grow iron nanoparticles with different metal nanoparticle distribution on the SFMO scaffold through a phase decomposition process in reducing atmospheres. We then investigate the electrochemical pumping of oxygen species from air in the cathode to the anode for the selective electro-oxidation of $\mathrm{CH}_{4}$ to $\mathrm{C}_{2} \mathrm{H}_{4}$. We finally study the electrochemical oxidation of $\mathrm{CH}_{4}$ to chemicals in the anode in conjunction with electrolysis of $\mathrm{CO}_{2}$ to $\mathrm{CO}$ in the cathode.

\section{Results}

Growth of exsolved interfaces. Figure 2a shows the X-ray diffraction (XRD) patterns of the oxidized $\mathrm{Sr}_{2} \mathrm{Fe}_{1.5+x} \mathrm{Mo}_{0.5} \mathrm{O}_{6-\delta}$ $(x=0-0.1)$ samples while the excess iron element is doped into the oxide lattice to form a series of homogeneous solid solutions. The chemical formulas of $\mathrm{Sr}_{2} \mathrm{Fe}_{1.5} \mathrm{Mo}_{0.5} \mathrm{O}_{6-\delta}, \mathrm{Sr}_{2} \mathrm{Fe}_{1.525} \mathrm{Mo}_{0.5} \mathrm{O}_{6-\delta}$, $\mathrm{Sr}_{2} \mathrm{Fe}_{1.55} \mathrm{Mo}_{0.5} \mathrm{O}_{6-\delta}, \mathrm{Sr}_{2} \mathrm{Fe}_{1.575} \mathrm{Mo}_{0.5} \mathrm{O}_{6-\delta}$, and $\mathrm{Sr}_{2} \mathrm{Fe}_{1.6} \mathrm{Mo}_{0.5} \mathrm{O}_{6-\delta}$ are denoted as SFMO, 0.025Fe-SFMO, 0.050Fe-SFMO, $0.075 \mathrm{Fe}-\mathrm{SFMO}$, and $0.100 \mathrm{Fe}-\mathrm{SFMO}$, respectively. The presence of excess iron in the host oxide lattice would result in metallic iron nanoparticles on the SFMO scaffold after reduction, producing the electrochemically active metal-oxide interfaces through a phase decomposition process. The iron in the host lattice is mainly present in the form of $\mathrm{Fe}^{3+/ 4+}$ oxidation state as shown in the X-ray photoelectron spectroscopy (XPS) in Supplementary Fig. 1. The oxidized sample has a porous microstructure with clean scaffold surface as shown in Supplementary Fig. 2, and the lattice spacing of $0.288 \mathrm{~nm}$ in the transmission electron microscopy (TEM) is in accordance with (002) plane. Figure $2 \mathrm{~b}$ shows the XRD of $\mathrm{Sr}_{2} \mathrm{Fe}_{1.5+x} \mathrm{Mo}_{0.5} \mathrm{O}_{6-\delta}(x=0-0.1)$ after reduction, confirming the presence of metallic iron phase that arises from the exsolution of excess iron dopant in the oxide lattice upon reduction. We further determine the oxygen nonstoichiometry of $\mathrm{Sr}_{2} \mathrm{Fe}_{1.5+x} \mathrm{Mo}_{0.5} \mathrm{O}_{6-\delta}(x=0-0.1)$ before and after reduction using iodometric titration and summarize the results in Supplementary Table 1. For the SFMO sample, the oxygen storage capacity is $0.2465 \mathrm{~mol}$ after reduction, indicating that the reversible oxygen loss may be mainly from the valence change of $\mathrm{Fe} / \mathrm{Mo}$ in the lattice, while no iron nanoparticle exsolution is observed in this process. After reduction, the excess iron $(x=$ $0.025-0.1$ ) has been transformed into metallic iron nanoparticles while the left iron remains unchanged in a fully oxidized state. The exsolution of iron nanoparticles further leads to oxygen loss which shows a strong dependence of oxygen nonstoichiometry on the exsolution of iron metal as shown in Supplementary Table 1, which again validates the exsolution of up to $95-100 \%$ excess iron from the oxide lattice through a phase decomposition process during reduction. Figure $2 \mathrm{c}$ shows the uniform metallic iron
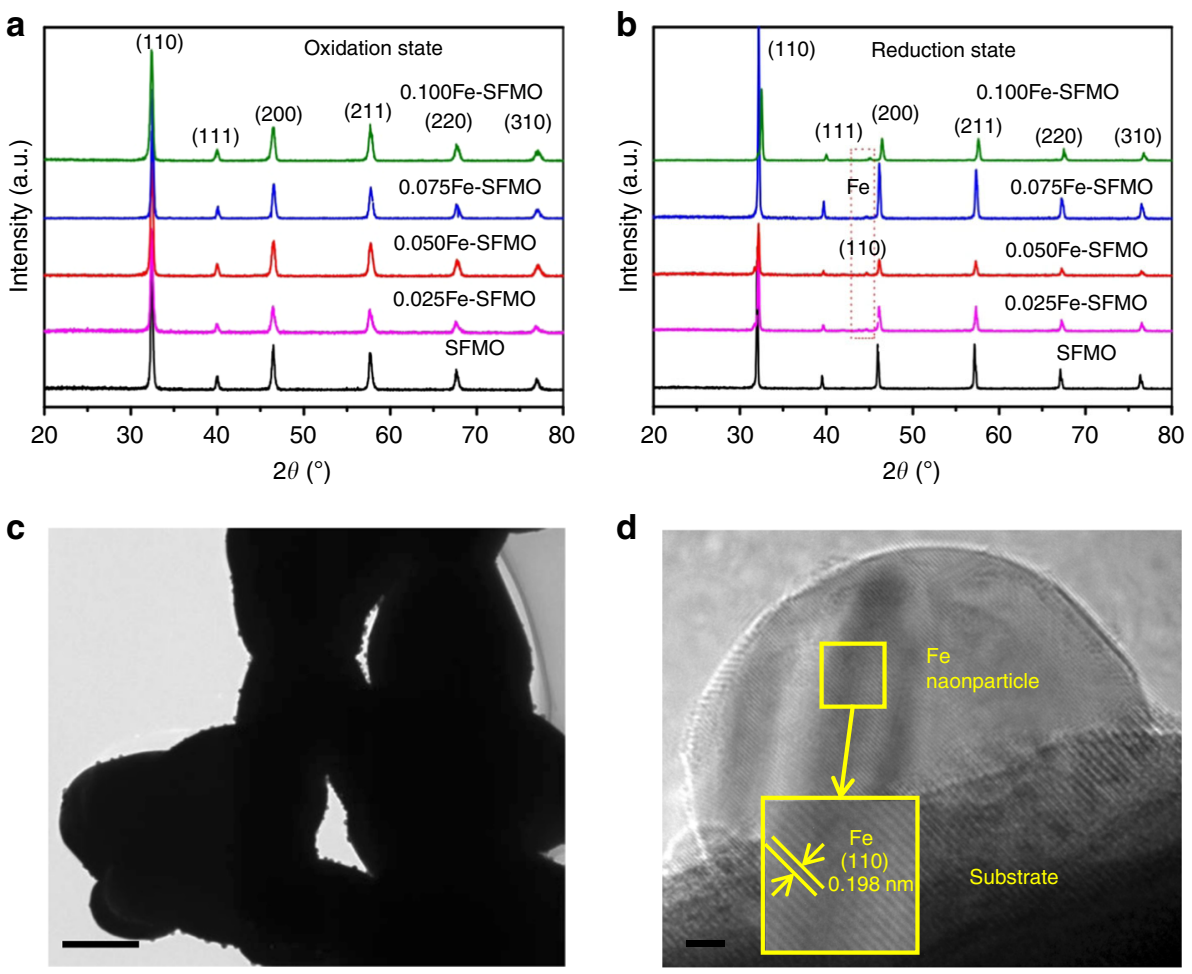

Fig. 2 X-ray diffraction patterns and micrographs. a X-ray diffraction (XRD) patterns of oxidized samples. b XRD patterns of reduced samples. c Highresolution transmission electron microscopy (HRTEM) view of iron nanoparticles and the scale bar is 500 nm. $\mathbf{d}$ Enlarged view of iron nanoparticle anchored on the SFMO surface after reduction and the scale bar is $2 \mathrm{~nm}$ 
nanoparticles with diameters of $\sim 25 \mathrm{~nm}$ anchoring on the SFMO oxide surface after reduction in hydrogen atmosphere, which confirms the in situ growth of metal-oxide interfaces through a phase decomposition process. Figure $2 \mathrm{~d}$ shows the in situ grown metal-oxide interfaces with the iron nanoparticles deeply embedded on the SFMO substrate, which demonstrates a clear heterojunction interface that is anticipated to produce strong interfacial interaction. At high temperature, the strong interface interactions at nanoscale would provide enhanced thermal stability against nanoparticle agglomerations and carbon deposition from $\mathrm{CH}_{4}$ pyrolysis.

SOEs with porous SFMO anodes are constructed while the cell microstructures are shown in Supplementary Fig. 3. We use $\mathrm{La}_{0.9} \mathrm{Sr}_{0.1} \mathrm{Ga}_{0.8} \mathrm{Mg}_{0.2} \mathrm{O}_{3-\delta}$ (LSGM) electrolyte with dimension of 1 $\mathrm{mm}$ in thickness and $20 \mathrm{~mm}$ in diameter. LSGM is an excellent oxygen-ion-conducting electrolyte with high ionic conductivity at intermediate to high temperatures and we conduct $\mathrm{CH}_{4}$ oxidation at $850^{\circ} \mathrm{C}$ to enhance the $\mathrm{C}_{2} \mathrm{H}_{4}$ yield. The electrochemical oxidation of $\mathrm{CH}_{4}$ in the anode is conducted in conjunction with $\mathrm{O}_{2}$ electrolysis from air in the cathode at $850^{\circ} \mathrm{C}$. The $\mathrm{CH}_{4} / \mathrm{O}_{2}$ fuel cell mode is a mode of electrochemical oxidation of $\mathrm{CH}_{4}$ with $\mathrm{O}_{2}$ gas toward $\mathrm{CO}_{2}$ generation driven by the oxygen gradient across two different electrodes in a concentration cell. Here we further apply voltages to boost the electrochemical $\mathrm{CH}_{4}$ oxidation process toward $\mathrm{C}_{2} \mathrm{H}_{4}$ generation in the presence of interface catalysis in the anode. Before operation, the anodes are pre-reduced using 5\% $\mathrm{H}_{2} / \mathrm{Ar}$ to in situ grow the exsolved interfaces that are composed of iron nanoparticles anchoring on the SFMO scaffolds. Supplementary Fig. 4 shows that the iron nanoparticles are grown on the SFMO scaffold and the size of the iron nanoparticles has a narrow distribution with a mean diameter of $\sim 25 \mathrm{~nm}$ after prereduction. Figure $3 \mathrm{a}$ shows that the current-voltage $(I-V)$ relationship clearly reveals the superior performance with up to
$100 \%$ enhancement of the SFMO cathodes with nanoscale metal-oxide interfaces in comparison to the bare cathode. The optimum chemical composition of the anode is found to be $0.075 \mathrm{Fe}-\mathrm{SFMO}$. The growth of metal-oxide interfaces drastically improves the current densities to $\sim 1 \mathrm{~A} \mathrm{~cm}^{-2}$ at $1.6 \mathrm{~V}$ with the presence of optimum length of metal-oxide interfaces in the porous SFMO scaffolds. Supplementary Fig. 5 shows that the electrode polarization resistance is as low as $\sim 0.4 \Omega \mathrm{cm}^{2}$ for the different anodes at the applied voltages of $1.6 \mathrm{~V}$, indicating the significantly enhanced electrode process at higher applied voltages. Figure $3 \mathrm{~b}$ shows the short-term operation of $\mathrm{CH}_{4}$ oxidation at different voltages, which again confirms the significantly enhanced electrochemical process with metal-oxide interfaces in the anodes. Figure $3 \mathrm{c}$ summarizes the electrode polarizations of the electrochemical oxidation of $\mathrm{CH}_{4}$ with different cathodes at $1.2-1.6 \mathrm{~V}$ at $850^{\circ} \mathrm{C}$. It is observed that the reduction of electrode polarization resistances strongly depends on the growth of metal-oxide interfaces in the electrode while higher applied voltage facilitates the electrochemical process and therefore enhances the electrode reaction kinetics. It should be noted that the overall electrode activity is enhanced with the growth of metal-oxide interfaces; however, more attentions need to be paid to the conversion of $\mathrm{CH}_{4}$ to $\mathrm{C}_{2} \mathrm{H}_{4}$ with less overoxidation of $\mathrm{CH}_{4}$ to $\mathrm{CO}_{2}$ in the porous anodes.

Methane conversion at interfaces. The properties of $\mathrm{CH}_{4}$ explain the exceptionally high molecule stability which therefore leads to the difficulties of $\mathrm{CH}_{4}$ activation and conversion. A limitation with most existing heterogeneous catalysts is that the initial $\mathrm{C}-\mathrm{H}$ bond cleavage is the rate controlling step. It is widely accepted that the oxidation reaction of $\mathrm{CH}_{4}$ to $\mathrm{C}_{2} \mathrm{H}_{4}$ is usually initiated on the surface of solid catalyst by reacting $\mathrm{CH}_{4}$ with surface oxygen
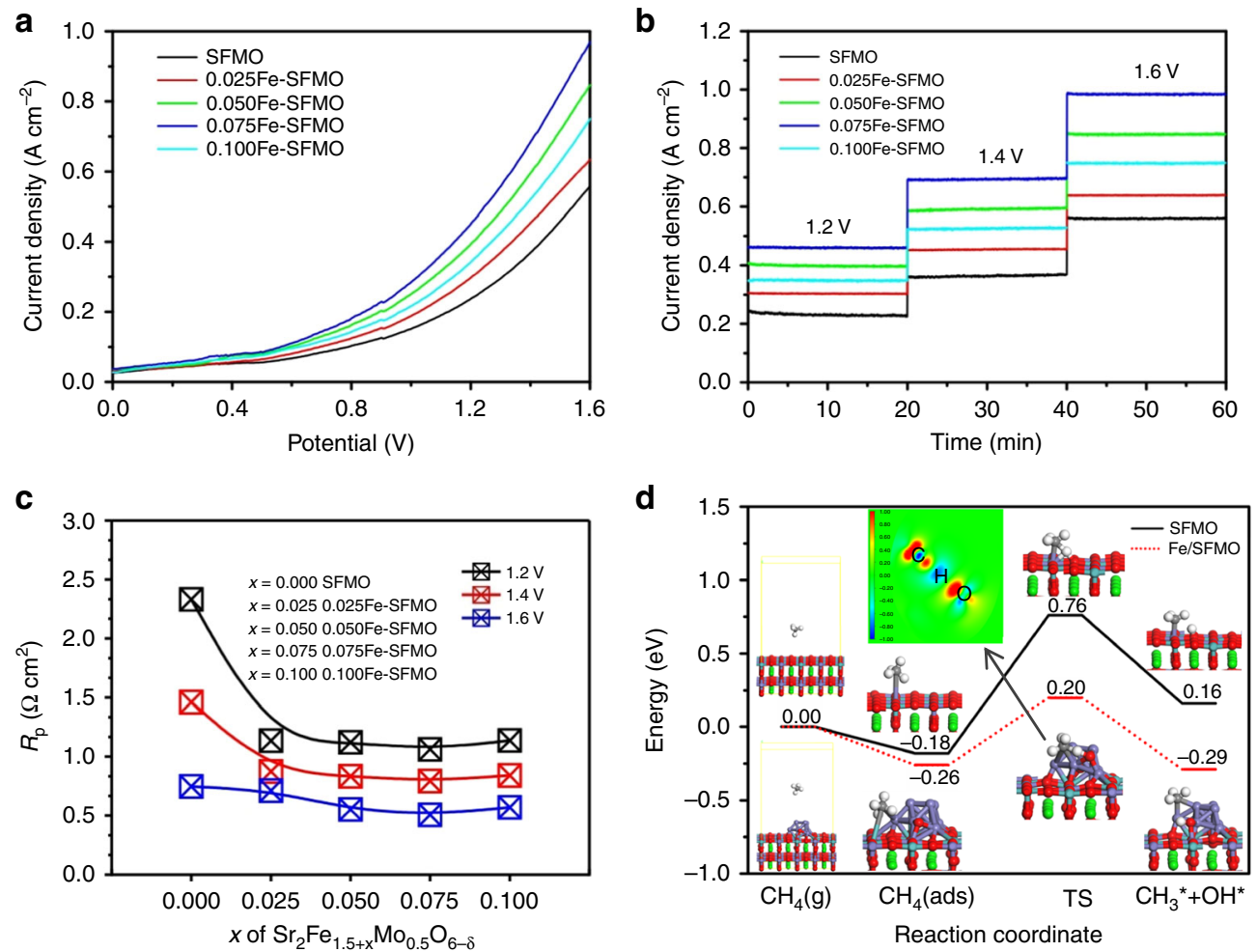

Fig. 3 Electrochemical oxidation of $\mathrm{CH}_{4}$ at the anode in conjunction with $\mathrm{O}_{2}$ electrolysis. a The current density-voltage (I-V) curves of the electrolyzers with different cathodes for $\mathrm{CH}_{4}$ oxidation at $850^{\circ} \mathrm{C}$. b The short-term operation of $\mathrm{CH}_{4}$ oxidation with the composite anodes at different voltages. $\mathbf{c}$ The electrode polarizations with different cathodes at $1.2-1.6 \mathrm{~V}$ at $850^{\circ} \mathrm{C}$. $\mathbf{d}$ Energy diagrams for adsorption and $\mathrm{C}-\mathrm{H}$ bond cleavage of $\mathrm{CH}_{4}$ on $\mathrm{SFMO}(001)$ and $\mathrm{Fe} / \mathrm{SFMO}$ (001) including their initial, transition, and final states. Inset: electronic charge density difference for the transition state of Fe/SFMO (001) 
species to form methyl radicals with the first $\mathrm{C}-\mathrm{H}$ bond cleavage, and then it continues in a gas-phase coupling step involving the coupling of methyl radicals to $\mathrm{C}_{2} \mathrm{H}_{6}$ followed by dehydrogenation to $\mathrm{C}_{2} \mathrm{H}_{4}^{8,28}$. In our work, the oxygen species are continuously produced and transported to the anode while the metal-oxide interfaces at nanoscale would be highly favorable to accommodate these active oxygen species to react with $\mathrm{CH}_{4}$ to initiate the first $\mathrm{C}-\mathrm{H}$ bond cleavage under external applied potentials. Here the theoretical calculations are tentatively conducted to understand the cleavage of $\mathrm{C}-\mathrm{H}$ bond in $\mathrm{CH}_{4}$ especially at the nanoscale metal-oxide interfaces. We firstly study the $\mathrm{CH}_{4}$ activation over the $(\mathrm{Fe} / \mathrm{Mo}) \mathrm{O}_{2}$ termination on the SFMO (001) surface as shown in Supplementary Fig. 6. In this step, a $\mathrm{CH}_{4}$ molecule from the feed gas dissociatively adsorbs on a metal site and a neighboring oxygen atom, forming a hydroxyl group with $\mathrm{O}$ on the surface and releasing a methyl radical. As shown in Fig. 3d and Supplementary Fig. 7, our calculations suggest that molecular adsorption of $\mathrm{CH}_{4}$ on one $\mathrm{Fe}$ site with the bond length of $3.263 \AA$ is energetically unfavorable. After the $\mathrm{C}-\mathrm{H}$ bond cleavage of $\mathrm{CH}_{4}$, the $\mathrm{CH}_{3}$ radical adsorbs on surface metal $\mathrm{Fe}$ with the bond length of $2.146 \AA$ and the $\mathrm{H}$ atom binds with the $\mathrm{O}$ atom of SFMO surface forming O-H bond $(0.987 \AA)$. And the energy barrier of hydrogen abstraction reaction is up to $1.0 \mathrm{eV}$ on the SFMO (001) surface, indicating an energetically unfavorable process for $\mathrm{CH}_{4}$ activation. In contrast, for the Fe/SFMO system, the $\mathrm{CH}_{4}$ mainly adsorbs at the interface between $\mathrm{Fe}$ clusters and SFMO surface. The adsorption energy of $\mathrm{CH}_{4}$ is $-0.26 \mathrm{eV}$, where the $\mathrm{CH}_{4}$ binds with the Mo atom (3.734 $\AA$ ) of the SFMO surface and together with the Fe atom (3.545 $\AA$ ) of Fe clusters. After the first $\mathrm{C}-\mathrm{H}$ bond cleavage of $\mathrm{CH}_{4}$, the $\mathrm{CH}_{3}$ radical adsorbs on the $\mathrm{Fe}$ atoms of $\mathrm{Fe}$ clusters with the bond lengths of 2.027 and $2.093 \AA$ while the $\mathrm{H}$ atom binds with the $\mathrm{O}$ atom at the Fe/SFMO interface forming $\mathrm{O}-\mathrm{H}$ bond $(0.980 \AA)$. The cleavage of $\mathrm{C}-\mathrm{H}$ bond in $\mathrm{CH}_{4}$ at the metal-oxide Fe/SFMO (001) interface is highly favorable with the energy barrier as low as only $0.46 \mathrm{eV}$. At this stage, active oxygen at metal-oxide interfaces would be present in the form of new oxygen species $\left(\mathrm{O}_{\mathrm{ads}}\right)$ to initiate the cleavage of $\mathrm{C}-\mathrm{H}$ bond in $\mathrm{CH}_{4}$. The energy barrier of oxygen transfer process through oxygen vacancy site is only $0.34 \mathrm{eV}$, as shown in Supplementary Fig. 8. Of course, the oxygen deficiency in SFMO would be favorable for $\mathrm{CH}_{4}$ activation and oxidation $^{14,29}$. As we know, the charge transfer from adsorbed $\mathrm{CH}_{4}$ molecule to catalyst surface may be another key factor in $\mathrm{CH}_{4}$ activation ${ }^{1}$. In the anode, the adsorbed $\mathrm{CH}_{4}$ coupled with active oxygen species would continuously donate free electron to external circuit under electrochemical potentials and thus facilitates $\mathrm{CH}_{4}$ activation at the metal-oxide interfaces. It can be therefore concluded that the metal-oxide interface with active oxygen species would be effective to accommodate the reaction of $\mathrm{C}-\mathrm{H}$ bond cleavage under externally applied potentials in the porous anode.

Figure 4a shows the product analysis result of electrochemical oxidation of $\mathrm{CH}_{4}$ with different composite anodes while the oxide ions are ionically pumped to the anodes from air in the cathode. $\mathrm{CH}_{4}$ with $100 \%$ concentration is supplied to the anode and the products from the anode exhaust stream are analyzed using an online gas chromatography. We firstly investigate the thermal splitting of $\mathrm{CH}_{4}$ to $\mathrm{C}_{2} \mathrm{H}_{4}$ without externally applied voltage and find that only $\sim 0.4 \% \mathrm{C}_{2} \mathrm{H}_{4} / \mathrm{C}_{2} \mathrm{H}_{6}$ is generated with $\mathrm{H}_{2}$ of around $1.6 \%$, as shown in Supplementary Fig. 9. We also observe slight carbon deposition in this process if without electrochemical pumping oxygen ions to the anodes. When voltages are applied to the cell, it is observed that both applied voltages and metal-oxide interfaces on the anode scaffold impact the electrochemical process. $\mathrm{C}_{2} \mathrm{H}_{4}$ has been formed and its concentrations show a strong and positive dependence on the applied potentials, which confirms the successful conversion of $\mathrm{CH}_{4}$ to $\mathrm{C}_{2} \mathrm{H}_{4}$ using this electrochemical approach. $\mathrm{C}_{2} \mathrm{H}_{6}$ has also been formed through
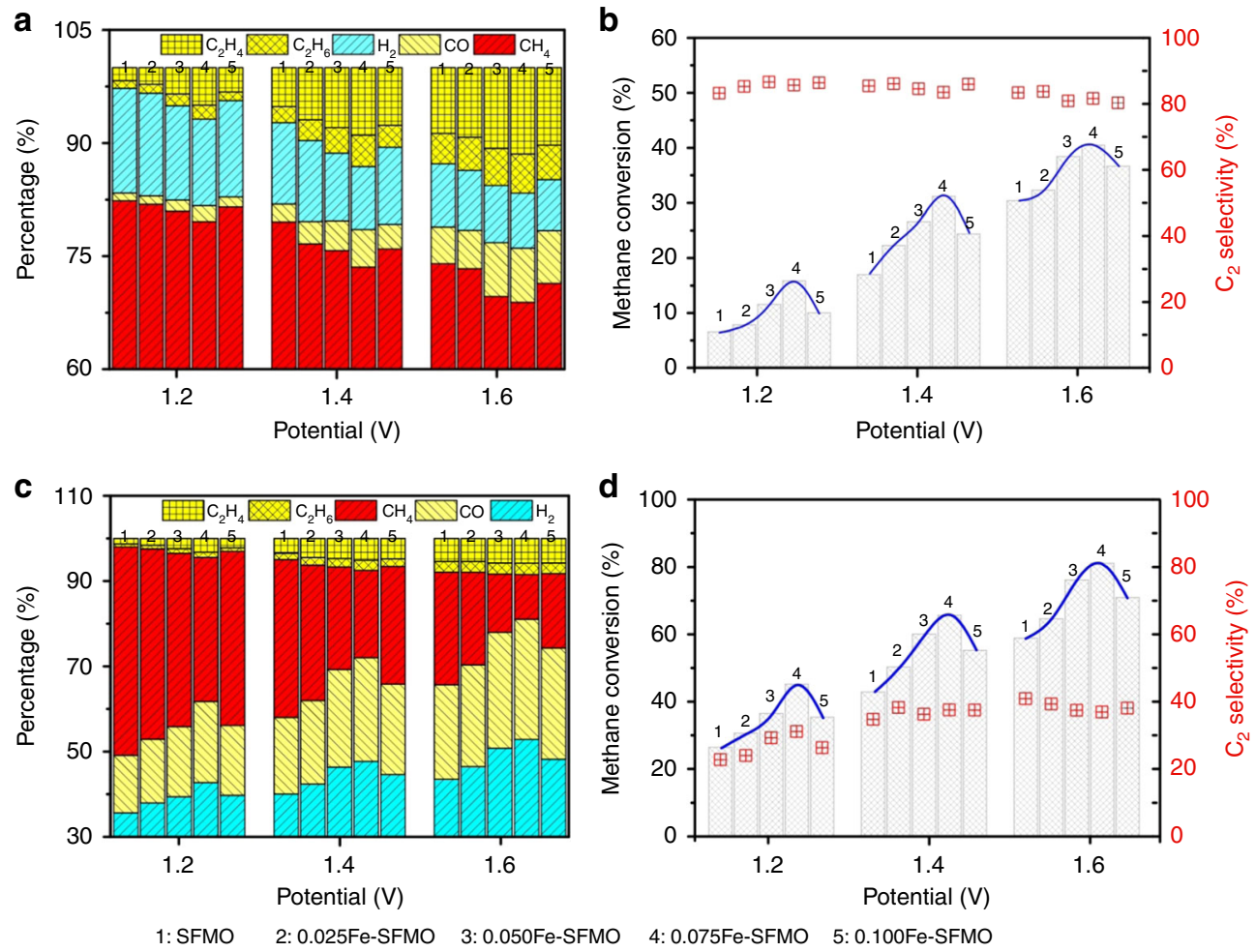

Fig. $4 \mathrm{CH}_{4}$ conversion and $\mathrm{C}_{2}$ selectivity in conjunction with $\mathrm{O}_{2}$ electrolysis. a The product analysis of electrochemical oxidation of $\mathrm{CH}_{4}$ with different anodes. $\mathbf{b} \mathrm{C}_{2}$ selectivity and $\mathrm{CH}_{4}$ conversion. $\mathbf{c}$ The product analysis of electrochemical $\mathrm{CH}_{4}$ oxidation with composite anodes. $\mathbf{d} \mathrm{CH}_{4}$ conversion and $\mathrm{C}_{2}$ selectivity after cycling the output gas 
the oxidative coupling of $\mathrm{CH}_{4}$ in the electrochemical conversion process while its concentrations are $\sim 1 / 3$ of the $\mathrm{C}_{2} \mathrm{H}_{4}$ concentrations. The by-products are mainly $\mathrm{H}_{2}$ together with small amount of $\mathrm{CO}$; however, their concentrations are in a close decreasing trend with the $\mathrm{C}_{2}\left(\mathrm{C}_{2} \mathrm{H}_{4}+\mathrm{C}_{2} \mathrm{H}_{6}\right)$ product generations. We show that the $\mathrm{C}_{2}$ products reach $16.7 \%\left(11.5 \% \mathrm{C}_{2} \mathrm{H}_{4}+5.2 \% \mathrm{C}_{2} \mathrm{H}_{6}\right)$ with $82.2 \% \quad \mathrm{C}_{2}$ selectivity while the $\mathrm{CH}_{4}$ conversion ratio is approaching as high as $40.5 \%$ in Fig. $4 \mathrm{~b}$ at ambient pressure and $1.6 \mathrm{~V}$. This represents the highest $\mathrm{C}_{2} \mathrm{H}_{4}$ yields and $\mathrm{C}_{2}$ selectivity in the reported catalytic conversion of $\mathrm{CH}_{4}$ including non-oxidative and oxidative conversion processes. The $\mathrm{C}$ atom efficiency is reaching $~ 98-100 \%$ with negligible over oxidation of $\mathrm{CH}_{4}$ to $\mathrm{CO}_{2}$, which further indicates the exceptionally high efficiency for $\mathrm{CH}_{4}$ conversion in this electrochemical process. The SFMO itself is an oxygen-nonstoichiometric catalyst and the iron species with unsaturated oxygen coordination at the SFMO surface would deliver catalytic activity. In contrast, redox stable $\mathrm{La}_{0.75} \mathrm{Sr}_{0.25} \mathrm{Cr}_{0.5} \mathrm{Mn}_{0.5} \mathrm{O}_{3-\delta}$ (LSCM) electrode without iron dopant in the lattice shows negligible catalysis activity toward $\mathrm{C}_{2} \mathrm{H}_{4}$ generation $^{11}$. It is also observed that the metal-oxide interfaces enhance $\mathrm{C}_{2}$ product generation by $\sim 50-100 \%$, indicating the favorable cleavage of $\mathrm{C}-\mathrm{H}$ bond at metal-oxide interfaces. Here the electrochemical processes are therefore dominated by the synergistic effect of the applied voltages and metal-oxide interfaces in the anodes. We further cycle the output gas for the electrochemical oxidation process and confirm that $\mathrm{CH}_{4}$ conversion has been enhanced to $\sim 81.1 \%$ in Fig. $4 c$; however, the main products are syngas while the $\mathrm{C}_{2}$ selectivity remains $\sim 41 \%$ (Fig. 4d). This indicates that the direct electrochemical oxidation of $\mathrm{CH}_{4}$ dominates the $\mathrm{C}_{2} \mathrm{H}_{4}$ generation, and the cycling oxidation degrades the $\mathrm{C}_{2}$ selectivity with the increase of syngas generation. We further conduct control experiment of electrochemical oxidation of $\mathrm{C}_{2} \mathrm{H}_{6}$ in the anode and we observe that the dominant products are $\mathrm{C}_{2} \mathrm{H}_{4}, \mathrm{CH}_{4}$, and $\mathrm{H}_{2}$ even without applied voltages as shown in Supplementary Fig. 10. This may be due to the thermal splitting of $\mathrm{C}_{2} \mathrm{H}_{6}$; however, significant coking is present in this process. When we apply voltage, the concentration of hydrocarbon product is slightly increased but the serious coking problem leads to rapid degradation of the cell performance. We therefore believe that the cycling oxidation increases syngas generation with enhanced $\mathrm{CH}_{4}$ conversion, while the $\mathrm{C}_{2}$ selectivity generally remains unchanged, indicating that the dominant $\mathrm{C}_{2}$ selectivity comes from the initial electrochemical oxidation process.

This simultaneous electrochemical process involves ionically pumping oxide ions from the cathode, across the electrolyte, to the anode for $\mathrm{CH}_{4}$ conversion. This feature provides an opportunity to convert oxygen-containing molecules, such as $\mathrm{CO}_{2}$ into $\mathrm{CO}$ while the $\mathrm{CH}_{4}$ conversion in the anode is maintained. Figure 5a shows the current-voltage $(I-V)$ relationship of $\mathrm{CO}_{2}$ electrolysis in the cathode in conjunction with $\mathrm{CH}_{4}$ oxidation in the anode in a simultaneous process. The growth of metal-oxide interfaces in the porous electrode scaffolds also improves the current densities while the optimum composition is $0.075 \mathrm{Fe}-\mathrm{SFMO}$ in which the content of metal nanoparticle dominates the metal-oxide interface length. Figure $5 \mathrm{~b}$ gives the dependence of $\mathrm{CO}$ generation from $\mathrm{CO}_{2}$ electrolysis both on metal-oxide interfaces and applied voltages, which indicates that the higher voltages facilitate $\mathrm{CO}_{2}$ reduction while optimum composition is the $0.075 \mathrm{Fe}-\mathrm{SFMO}$ composite with proper interface length. Figure $5 \mathrm{c}$ shows the $\mathrm{CH}_{4}$ conversion toward chemicals in the anode while the $\mathrm{CO}_{2}$ electrolysis is simultaneously performed in the cathode. Similar phenomenon has been observed for the performance dependence on the synergy of
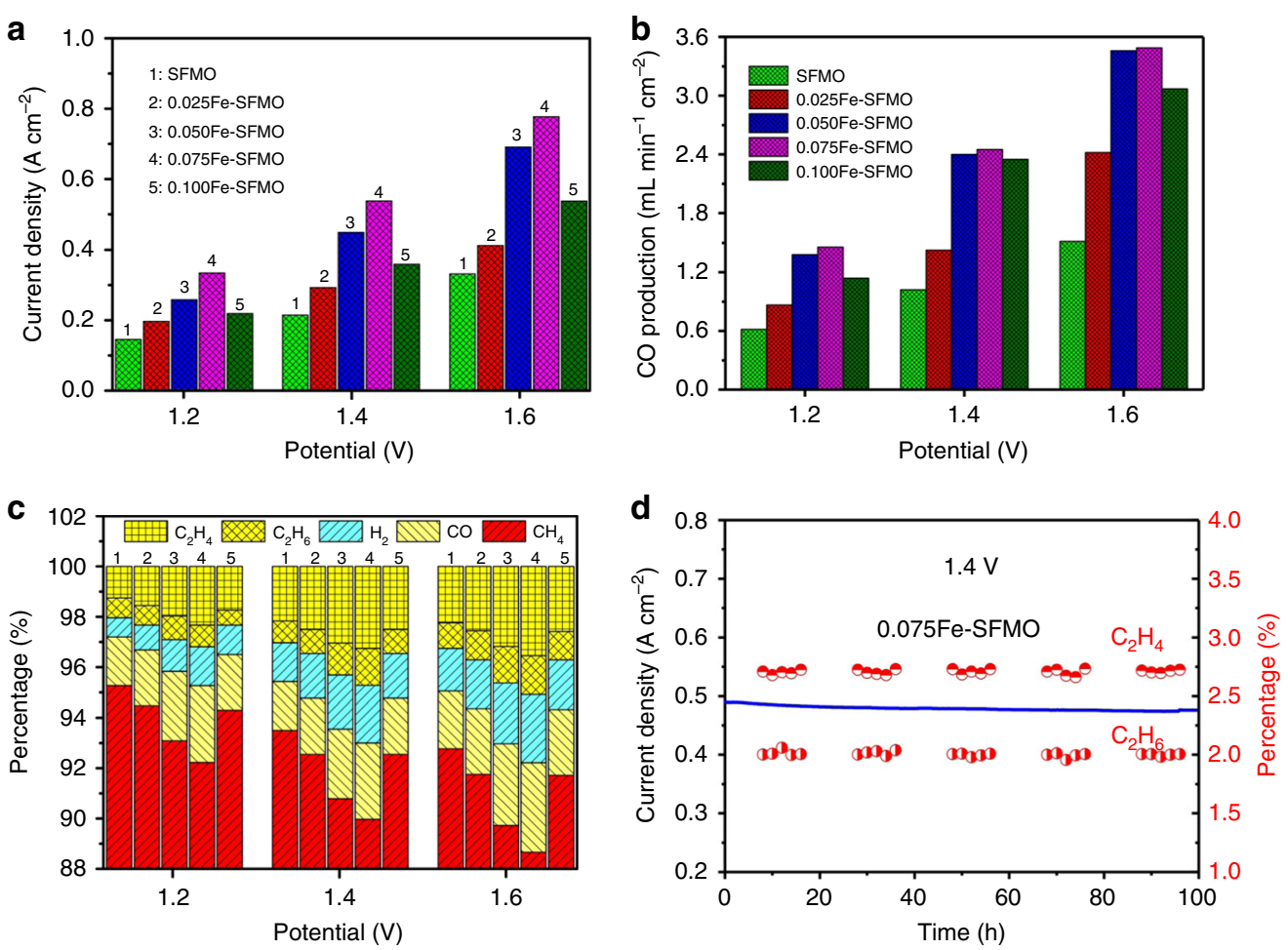

1: SFMO 2: 0.025Fe-SFMO 3: 0.050Fe-SFMO 4: 0.075Fe-SFMO 5: 0.100Fe-SFMO

Fig. 5 Electrochemical oxidation of $\mathrm{CH}_{4}$ in conjunction with $\mathrm{CO}_{2}$ electrolysis. a The current-voltage $(I-V)$ relationship of $\mathrm{CO}_{2}$ electrolysis with $\mathrm{CH}_{4}$ oxidation at $850^{\circ} \mathrm{C}$. $\mathbf{b} \mathrm{CO}$ production in the cathode at various voltages. $\mathbf{c}$ The product analysis in the anode. $\mathbf{d}$ The long-term performance of the $0.075 \mathrm{Fe}-\mathrm{SFMO}-\mathrm{SDC}$ electrode for $\mathrm{CH}_{4}$ oxidation with $\mathrm{CO}_{2}$ electrolysis at $850^{\circ} \mathrm{C}$ 
applied voltages and metal-oxide interfaces on the anode scaffold. The $\mathrm{C}_{2}$ products reach $2.04-5.08 \%\left(\mathrm{C}_{2} \mathrm{H}_{4}+\mathrm{C}_{2} \mathrm{H}_{6}\right)$ with $75.6 \% \mathrm{C}_{2}$ selectivity while the $\mathrm{CH}_{4}$ conversion ratio reaches $6.02-13.72 \%$ in the anode as shown in Fig. $5 \mathrm{c}$ at ambient pressure and $1.2-1.6 \mathrm{~V}$. This lower performance of $\mathrm{CO}_{2} / \mathrm{CH}_{4}$ conversion in contrast to $\mathrm{O}_{2} / \mathrm{CH}_{4}$ conversion in the electrochemical process would be attributed to the higher thermodynamic and kinetic barrier of $\mathrm{CO}_{2}$ electrolysis than $\mathrm{O}_{2}$ splitting in the cathode under applied potentials. However, these performances of $\mathrm{CH}_{4}$ conversion and $\mathrm{C}_{2}$ yields/selectivity are still much higher or comparable to the reported work in catalytic $\mathrm{CH}_{4}$ conversion including nonoxidative and oxidative conversion processes. We calculate the current efficiency and the results are shown in Supplementary Fig. 11. The current efficiency can reach $\sim 100 \%$ for the $\mathrm{O}_{2}$ electrolysis in conjunction with $\mathrm{CH}_{4}$ oxidation in the anode. However, the current efficiency can only reach $\sim 80 \%$ for $\mathrm{CO}_{2}$ electrolysis with simultaneous $\mathrm{CH}_{4}$ oxidation in the anode. Electrolysis of $\mathrm{O}_{2}$ is highly favorable and much easier than $\mathrm{CO}_{2}$ electrolysis even under the similar operation conditions. We believe that the current leakage may be present in $\mathrm{CO}_{2}$ electrolysis in the cathode, which therefore leads to lower $\mathrm{CH}_{4}$ conversion under the similar conditions. The loss of current efficiency may be due to the transport of impurities including p-type hole conduction in the LSGM electrolyte, which therefore limits the transport of oxygen species and accordingly degrades the $\mathrm{CH}_{4}$ conversion and hydrocarbon generation.

Long-term stability of $\mathrm{CH}_{4}$ conversion at high temperature remains a major challenge due to the nanoparticle agglomeration and carbon deposition leading to performance degradation ${ }^{8}$. In this work, the iron nanoparticles are exsolved and anchored on porous SFMO scaffold through a phase decomposition process, which is expected to possess enhanced high-temperature stability against nanoparticle agglomeration. For $\mathrm{CH}_{4}$ conversion, carbon deposition is another challenge that leads to severe deactivation of metal nanoparticles. The carbon coking normally originates from the disproportionation of $\mathrm{CO}$ and the pyrolysis of $\mathrm{CH}_{4}$. As shown in Fig. 5d, the all ceramic symmetric cell demonstrates excellent stability even after 10 redox cycles and $100 \mathrm{~h}$ of operations within the frames of these experiments. The details of durability tests are shown in Supplementary Fig. 12. The generation and selectivity of $\mathrm{C}_{2}$ hydrocarbons remain stable even after such a tough operation at high temperatures. The exsolved metal/oxide interfaces at nanoscale are expected to improve both long-term and redox stability by preventing nanoparticle coalescence driven by surface energy reduction. One reason may be that the strong interactions at the exsolved metal-oxide interfaces produce typical interfacial charge transfer to enhance coking resistance at high temperatures. The other important reason would be that the carbon removal at the interfaces is highly favorable with electrochemically provided oxygen species in the anode because the oxygen ions are continuously transported from the cathode to the anode under externally applied voltages, which would electrochemically oxidize the deposited carbon to carbon monoxide gas, and thus substantially enhance coking resistance. We further use SEM to observe the porous electrode before and after the redox cycling experiments over $100 \mathrm{~h}$. In Supplementary Fig. 13, we can see the clear microstructures of the porous electrode which well adheres to the LSGM electrolyte. After the redox cycling experiment over $100 \mathrm{~h}$, we still observe the porous electrode adhered well to the LSGM electrolyte, indicative of the strong interface interaction between the electrode and the electrolyte. However, it should be noted that the iron nanoparticles generally remain unchanged while no obvious carbon deposition is observed, which again demonstrates enhanced resistance to nanoparticle agglomeration, sintering, and coking due to the anchored interface in the porous electrode.

\section{Discussion}

In conclusion, we demonstrate a conceptually different approach of highly efficient conversion of $\mathrm{CH}_{4}$ to $\mathrm{C}_{2} \mathrm{H}_{4}$ with exceptionally high $\mathrm{C}_{2} \mathrm{H}_{4}$ yield and $\mathrm{C}_{2}$ selectivity in a solid oxide electrolyzer. The growth of metal-oxide interfaces at nanoscale with strong interactions in the porous electrode scaffolds possesses not only improved activity of $\mathrm{CH}_{4}$ activation but also enhanced coking resistance and thermal stability. Electrochemical oxidation of $\mathrm{CH}_{4}$ in the anode in conjunction with $\mathrm{O}_{2}$ electrolysis in the cathode shows the highest $\mathrm{C}_{2}$ yields of $16.7 \%\left(11.5 \% \mathrm{C}_{2} \mathrm{H}_{4}+5.2 \% \mathrm{C}_{2} \mathrm{H}_{6}\right)$ with $82.2 \% \mathrm{C}_{2}$ selectivity and exceptionally high durability even after $100 \mathrm{~h}$ of high temperature operation. Another efficient process with high $\mathrm{C}_{2}$ yields has also been demonstrated with electrochemical oxidation of $\mathrm{CH}_{4}$ in the anode in conjunction with $\mathrm{CO}_{2}$ electrolysis in the cathode. The active oxygen species electrochemically pumped to the confined metal-oxide interface in the anode scaffold enable both carbon removal and $\mathrm{CH}_{4}$ activation. This strategy provides a reliable and efficient electrochemical process for conversion of $\mathrm{CH}_{4}$ into valuable chemicals. The growth of the metal-oxide interface can give rise to an interfacial interaction that facilitates catalytic conversion using $\mathrm{CeO}_{2}, \mathrm{SrTiO}_{3}, \mathrm{TiO}_{2}$, and $\mathrm{MnO}_{2}$ substrates. The catalytically active $\mathrm{Fe}$ or Ni can be directly doped into the lattice of the oxide substrate during materials synthesis, and then the metal nanoparticles would be grown to anchor on the oxide surface after reduction. These metal-oxide interfaces with enhanced stability and coking resistance could have broad potential applications in many other catalysis fields.

\section{Methods}

Synthesis. Synthesis of SFMO, 0.025Fe-SFMO, 0.050Fe-SFMO, 0.075Fe-SFMO, and $0.100 \mathrm{Fe}-\mathrm{SFMO}\left(\mathrm{Sr}_{2} \mathrm{Fe}_{1.5+x} \mathrm{Mo}_{0.5} \mathrm{O}_{6-\delta} ; x=0-0.1\right)$ were carried out by a microwave-assisted combustion method ${ }^{25}$. The $\mathrm{Ce}_{0.8} \mathrm{Sm}_{0.2} \mathrm{O}_{2-\delta}$ (SDC) powders were synthesized using a combustion method ${ }^{14}$. LSGM was prepared by using a traditional solid-state reaction method ${ }^{10,25}$.

Characterization. XRD (Miniflex 600, Japan) and XPS (ESCALAB 250Xi, USA) were used to analyze the phase formation of samples and elemental states before and after reduction, respectively. The oxygen nonstoichiometry of $\mathrm{Sr}_{2} \mathrm{Fe}_{1.5}$ ${ }_{+} \mathrm{Mo}_{0.5} \mathrm{O}_{6-\delta}(x=0-0.1)$ before and after reduction was determined using iodometric titration ${ }^{30}$. The microstructures of the samples and the exsolution of nanoparticles were analyzed using scanning electron microscopy (SEM; SU-8010, Japan) and high-resolution transmission electron microscopy (HRTEM; Tecnai F20, USA).

Electrochemical measurements. The $\mathrm{Sr}_{2} \mathrm{Fe}_{1.5+x} \mathrm{Mo}_{0.5} \mathrm{O}_{6-\delta}(x=0-0.1)$ and SDC powders were mixed with a weight ratio of 65:35 and a suitable amount of cellulose and $\alpha$-terpineol were added to prepare electrode slurry. The 1-mm-thick LSGM disks were used as the electrolyte support to assemble single cells with different electrodes $\left(1 \mathrm{~cm}^{2}\right)$ using a brush printing method followed by heat treatments at $1100{ }^{\circ} \mathrm{C}$ for $3 \mathrm{~h}$ in air. The silver current collector with $0.18 \mathrm{~mm}$ in diameter was coated on the electrode surfaces and then heat-treated in air at $550{ }^{\circ} \mathrm{C}$ for $0.5 \mathrm{~h}$. For electrochemical tests of $\mathrm{CH}_{4}$ oxidation, the in situ AC impedance, long-term stability tests and the current density-voltage curve ( $I-V$ curve) were recorded using an electrochemical workstation (Zahner IM6, Germany). The $\mathrm{CH}_{4}, \mathrm{C}_{2} \mathrm{H}_{4}, \mathrm{C}_{2} \mathrm{H}_{6}$, $\mathrm{CO}$, and $\mathrm{H}_{2}$ in the output gas were analyzed uisng an online gas chromatograph (GC; Shimazu 2014, Japan).

Theoretical calculations. Spin-polarized DFT $+U$ theory calculations were performed using a plane wave basis set Vienna Ab-initio Simulation Package (VASP) $\operatorname{code}^{28,29}$. The generalized gradient approach (GGA) was used including Perdew-Burke-Ernzerhof (PBE) functional to describe exchange and correlation. The interaction between core and valence electrons was described with the projector augmented wave (PAW) method. The energies and residual forces were converged to $10^{-6} \mathrm{eV}$ and $0.02 \mathrm{eV} \AA^{-1}$, respectively. The plane wave cut-off used for energy calculations was set to $800 \mathrm{eV}$ and the $U-J$ value for Fe was set to $4.0 \mathrm{eV}$ while no $U-J$ parameter was used for Mo. The $\mathrm{Sr}_{2} \mathrm{Fe}_{1.5} \mathrm{Mo}_{0.5} \mathrm{O}_{6}$ cubic supercells of bulk SFMO with different distributions of Mo atoms were optimized with a $4 \times$ $4 \times 4 k$-point grid and only the $(\mathrm{Fe} / \mathrm{Mo}) \mathrm{O}_{2}$ terminated surfaces were considered because they were expected to be more catalytically active than the SrO termination. By comparison of stability, the $(\mathrm{Fe} / \mathrm{Mo}) \mathrm{O}_{2}$ terminated surface model constructed from the plane diagonal-Mo bulk structure $(a=b=c=7.8717 \AA$, 
$\left.\alpha=\beta=\gamma=90^{\circ}\right)$ was used to simulate the (001) surface. A $p(2 \times 2)$ superstructure with four layers (160 atoms) of the (001) surface of SFMO was used to simulate the periodic slab model. The vacuum region is $15 \AA$. The Fe segregation on the (001) surface slab of SFMO was mimicked by a cluster containing with $9 \mathrm{Fe}$ atoms laying on the (001) surface of SFMO. A $2 \times 2 \times 1 k$-point grid was used for Brillouin zone sampling of (001) Fe/SFMO surface system. The adsorption energy of $\mathrm{CH}_{4}$ with van der Waals Correction was calculated using the equation of

$E_{\text {ads }}=E_{\text {total }}-E_{\text {Substrate }}-E_{\mathrm{CH}_{4}}$, where $E_{\text {total }}$ is the total energy of the adsorption system, $E_{\text {Substrate }}$ and $E_{\mathrm{CH}_{4}}$ are the energy of the system without adsorption and the energy of the $\mathrm{CH}_{4}$ in gas phase, respectively ${ }^{10}$. The climbing-image nudged elastic band (CI-NEB) method was employed to calculate the energy barrier of oxygen vacancy transfer and the $\mathrm{C}-\mathrm{H}$ bond cleavage in $\mathrm{CH}_{4}$ reaction processes ${ }^{14}$.

\section{Date availability}

The data supporting the findings of this study are available from the corresponding authors upon reasonable request.

Received: 14 August 2018 Accepted: 18 February 2019

Published online: 12 March 2019

\section{References}

1. Schwach, P., Pan, X. L. \& Bao, X. H. Direct conversion of methane to valueadded chemicals over heterogeneous catalysts: challenges and prospects. Chem. Rev. 117, 8497-8520 (2017)

2. Zhong, L. S. et al. Cobalt carbide nanoprisms for direct production of lower olefins from syngas. Nature 538, 84-87 (2016).

3. Torres Galvis, H. M. \& de Jong, K. P. Catalysts for production of lower olefins from synthesis gas: a review. ACS Catal. 3, 2130-2149 (2013).

4. Jiao, F. et al. Shape-selective zeolites promote ethylene formation from syngas via a ketene intermediate. Angew. Chem. Int. Ed. 57, 4692-4696 (2018).

5. Jiao, F. et al. Selective conversion of syngas to light olefins. Science $\mathbf{3 5 1}$ 1065-1068 (2016).

6. Schwach, P. et al. Structure sensitivity of the oxidative activation of methane over MgO model catalysts: II. Nature of active sites and reaction mechanism. J. Catal. 329, 574-587 (2015)

7. Noon, D., Seubsai, A. \& Senkan, S. Oxidative coupling of methane by nanofiber catalysts. Chem CatChem 5, 146-149 (2013).

8. Guo, X. G. et al. Direct, nonoxidative conversion of methane to ethylene, aromatics, and hydrogen. Science 344, 616-619 (2014).

9. Bi, L., Boulfrad, S. \& Traversa, E. Steam electrolysis by solid oxide electrolysis cells (SOECs) with proton-conducting oxides. Chem. Soc. Rev. 43, 8255-8270 (2014).

10. $\mathrm{Lu}, \mathrm{J}$. H. et al. Highly efficient electrochemical reforming of $\mathrm{CH}_{4} / \mathrm{CO}_{2}$ in a solid oxide electrolyser. Sci. Adv. 4, 8 (2018).

11. Gan, L. Z., Ye, L. T., Ruan, C., Chen, S. G. \& Xie, K. Redox-reversible iron orthovanadate cathode for solid oxide steam electrolyzer. Adv. Sci. 3, 7 (2016).

12. Xie, K., Zhang, Y. Q., Meng, G. Y. \& Irvine, J. T. S. Direct synthesis of methane from $\mathrm{CO}_{2} / \mathrm{H}_{2} \mathrm{O}$ in an oxygen-ion conducting solid oxide electrolyser. Energy Environ. Sci. 4, 2218-2222 (2011).

13. Zheng, Y. et al. A review of high temperature co-electrolysis of $\mathrm{H}_{2} \mathrm{O}$ and $\mathrm{CO}_{2}$ to produce sustainable fuels using solid oxide electrolysis cells (SOECs): advanced materials and technology. Chem. Soc. Rev. 46, 1427-1463 (2017).

14. Ye, L. T. et al. Enhancing $\mathrm{CO}_{2}$ electrolysis through synergistic control of nonstoichiometry and doping to tune cathode surface structures. Nat. Commun. 8 , 14785 (2017)

15. Nößler, M. et al. Generation of oxygen radical centers in binary neutral metal oxide clusters for catalytic oxidation reactions. Angew. Chem. Int. Ed. 49 , 407-410 (2010).

16. Choi, Y. M., Mebane, D. S., Lin, M. C. \& Liu, M. L. Oxygen reduction on $\mathrm{LaMnO}_{3-\delta}$ cathode materials in solid oxide fuel cells. Chem. Mater. 19, 1690-1699 (2007).

17. Wang, J. H., Liu, M. L. \& Lin, M. C. Oxygen reduction reactions in the SOFC cathode of $\mathrm{Ag} / \mathrm{CeO}_{2}$. Solid State Ion. 177, 939-947 (2006).

18. Yang, W. Q. et al. Enhanced catalytic activity toward $\mathrm{O}_{2}$ reduction on Ptmodified $\mathrm{La}_{1-\mathrm{x}} \mathrm{Sr}_{\mathrm{x}} \mathrm{Co}_{1-\mathrm{y}} \mathrm{Fe}_{\mathrm{y}} \mathrm{O}_{3-\delta}$ cathode: a combination study of first-principles calculation and experiment. ACS Appl. Mater. Interfaces 6, 21051-21059 (2014).

19. Palmer, M. S., Neurock, M. \& Olken, M. M. Periodic density functional theory study of methane activation over $\mathrm{La}_{2} \mathrm{O}_{3}$ : Activity of $\mathrm{O}^{2-}, \mathrm{O}^{-}, \mathrm{O}_{2}{ }^{2-}$, oxygen point defect, and $\mathrm{Sr}^{2+}$-Doped Surface Sites. J. Am. Chem. Soc. 124, 8452-8461 (2002).
20. Fu, Q., Yang, F. \& Bao, X. H. Interface-confined oxide nanostructures for catalytic oxidation reactions. Acc. Chem. Res. 46, 1692-1701 (2013).

21. Yang, F., Deng, D. H., Pan, X. L., Fu, Q. \& Bao, X. H. Understanding nano effects in catalysis. Natl Sci. Rev. 2, 183-201 (2015).

22. Neagu, D., Tsekouras, G., Miller, D. N., Menard, H. \& Irvine, J. T. S. In situ growth of nanoparticles through control of non-stoichiometry. Nat. Chem. $\mathbf{5}$, 916-923 (2013)

23. Myung, J. H., Neagu, D., Miller, D. N. \& Irvine, J. T. S. Switching on electrocatalytic activity in solid oxide cells. Nature 537, 528-531 (2016).

24. Irvine, J. T. S. et al. Evolution of the electrochemical interface in hightemperature fuel cells and electrolysers. Nat. Energy 1, 13 (2016).

25. Liu, B. Q., Dong, X. H., Xiao, G. L., Zhao, F. \& Chen, F. L. A novel electrode material for symmetrical SOFCs. Adv. Mater. 22, 5478-5482 (2010).

26. Tao, S. W., Canales-Vazquez, J. \& Irvine, J. T. S. Structural and electrical properties of the perovskite oxide $\mathrm{Sr}_{2} \mathrm{FeNbO}_{6}$. Chem. Mater. 16, 2309-2316 (2004).

27. Cowin, P. I., Petit, C. T. G., Lan, R., Irvine, J. T. S. \& Tao, S. W. Recent progress in the development of anode materials for solid oxide fuel cells. Adv. Energy Mater. 1, 314-332 (2011).

28. Cui, X. J. et al. Room-temperature methane conversion by graphene-confined single iron atoms. Chem. 4, 1-9 (2018).

29. Hong, T., Zhao, M. Y., Brinkman, K., Chen, F. L. \& Xia., C. R. Enhanced oxygen reduction activity on Ruddlesden-Popper phase decorated $\mathrm{La}_{0.8} \mathrm{Sr}_{0.2} \mathrm{FeO}_{3-\delta} 3 \mathrm{D}$ heterostructured cathode for solid oxide fuel cells. ACS Appl. Mater. Interfaces 9, 8659-8668 (2017).

30. Nazzal, A. I. et al. New procedure for determination of $[\mathrm{Cu}-\mathrm{O}]^{+\mathrm{p}}$ charge and oxygen-content in high- $\mathrm{T}_{\mathrm{C}}$ copper oxides. Physica C 153, 1367-1368 (1988).

\section{Acknowledgements}

K.X. acknowledges the National Key Research and Development Program of China (2017YFA0700102), the Natural Science Foundation of China (91845202), Dalian National Laboratary for Clean Eenrgy (DNL180404) and the Strategic Priority Research Program of the Chinese Academy of Sciences (XDB2000000). F.C. acknowledges the U.S. National Science Foundation (DMR-1832809).

\section{Author contributions}

C.Z., S.H. and J.L. conducted the experiments. X.H. conducted the first principle calculations. F.C. provided useful discussion and polished the English. K.X. supervised this work. All authors were involved in the data analysis and discussion.

\section{Additional information}

Supplementary Information accompanies this paper at https://doi.org/10.1038/s41467 019-09083-3.

Competing interests: The authors declare no competing interests.

Reprints and permission information is available online at http://npg.nature.com/ reprintsandpermissions/

Journal peer review information: Nature Communication would like to thank the anonymous reviewer for their contribution to the peer review of this work. Peer review reports are available.

Publisher's note: Springer Nature remains neutral with regard to jurisdictional claims in published maps and institutional affiliations.

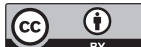

Open Access This article is licensed under a Creative Commons Attribution 4.0 International License, which permits use, sharing, adaptation, distribution and reproduction in any medium or format, as long as you give appropriate credit to the original author(s) and the source, provide a link to the Creative Commons license, and indicate if changes were made. The images or other third party material in this article are included in the article's Creative Commons license, unless indicated otherwise in a credit line to the material. If material is not included in the article's Creative Commons license and your intended use is not permitted by statutory regulation or exceeds the permitted use, you will need to obtain permission directly from the copyright holder. To view a copy of this license, visit http://creativecommons.org/ licenses/by/4.0/

(c) The Author(s) 2019 